\title{
A Conceptual Model of Medical Tourism Service Supply Chain
}

\author{
Saliha Karadayi-Usta iD, Seyda SerdarAsan iD \\ Istanbul Technical University (Turkey) \\ salihakaradayiusta@gmail.com,serdars@itu.edu.tr
}

Received: September 2019

Accepted: March 2020

\begin{abstract}
:
Purpose: Medical tourism service requires involvement of multiple parties from the service network, however medical tourism is not well studied from a supply chain management perspective. This study suggests a conceptual model of medical tourism service supply chain (MTSSC) to provide a clearer understanding of its nature, and defines its business processes.

Design/methodology/approach: Triangulation which makes use of literature review, in-depth interviews, and expert evaluations was applied to develop and validate the suggested model. The proposed model is initialized based on the relevant literature. In-depth interviews were used to refine and finalize the model. Expert evaluations ensure the trustworthiness of the model and the business process definitions.
\end{abstract}

Findings: The proposed model uses a nested process structure rather than a one-dimensional supply chain model, where the assistance company maintains an intermediary role between the patient and all the service providers (e.g. medical institutions, transportation, accommodation). Additionally, the conceptual model identifies seven business processes: service design, service recovery management, customer relationship management, supplier relationship management, demand management, capacity and resource management, and service delivery management.

Practical implications: The results provide a better understanding of the MTSSC structure and processes, and a recognition of the MTSSC members. The process definitions give the members an idea about their roles in the service design and delivery in practice. Additionally, a better understanding of the system as a whole leads to better process development and control. MTSSC members may shape their organizations internally and supply chain-wide by considering this conceptual model. Moreover, the model acts as a basis for supply chain collaboration decisions.

Originality/value: The conceptual model is built upon the theories and practice of medical tourism services, supply chain management, and service operations management. This study contributes to the theory of medical tourism services management by explaining the MTSSC concepts and business processes, and extends existing knowledge.

Keywords: medical tourism, medical tourism service supply chain, supply chain business processes, triangulation, conceptual model

\section{To cite this article:}

Karadayi-Usta, S., \& SerdarAsan, S. (2020). A Conceptual Model of Medical Tourism Service Supply Chain. Journal of Industrial Engineering and Management, 13(2), 246-265. https:/ /doi.org/10.3926/jiem.3008 


\section{Introduction}

Medical tourism is emerging both as a business and as an academic research area (Lee \& Fernando, 2015). Medical tourism refers to the type of healthcare tourism where patients have access to medical institutions for treatment/rehabilitation outside their country of residence. Although the terms medical tourism and healthcare tourism are often used interchangeably, healthcare tourism is an umbrella term that encompasses thermal health tourism, spa-wellness tourism, and elderly/disabled tourism along with medical tourism. Examples of medical tourism treatments include cardiovascular surgery, radiotherapy, organ transplantation, infertility and IVF procedures, aesthetic/plastic surgery, dialysis treatment and dental and eye care. Medical tourism is especially preferred by patients those seek to combine treatment with a vacation. It presents several advantages such as access to high quality and reliable medical services, immediate access to medical treatment without any queues or long waiting-periods, access to medical institutions equipped with cutting-edge technology and skilled healthcare professionals, travel to foreign cities and countries, and affordable prices (Connell, 2006; Glinos, Baeten \& Boffin, 2006; Kumar, Breuing \& Chahal 2012). Medical tourism is also considered an opportunity for healthcare innovation and a new area of investment (Connell, 2006) especially for developed countries like Turkey (Healthcare Travel Coordination Council, 2012).

Medical tourism treatment types can be categorized as elective and urgent/semi-urgent with a low-to-high-risk scale (Mason \& Spencer, 2017). This study focuses on elective treatments such as dental treatment and smile design, laser eye surgery, and hair transplantation.

The most popular destinations in the medical tourism market are Thailand, India, Costa Rica, Mexico, Malaysia, Singapore, Brazil, Colombia, Turkey, Taiwan, South Korea, Czech Republic, and Spain (Grand View Research, 2019; Mordor Intelligence Report, 2020). For example, Europe dental tourism market is led by Hungary, Poland, Spain, Turkey and Bulgaria, while in the Asia Pacific market, the major clinics/hospitals offering dental treatments are located in India, Thailand, Malaysia, South Korea, Philippines. Additionally, Central \& South America market's well-known hosting countries are Mexico, Brazil, Colombia and Costa Rica (Adroit Market Research, 2018). Turkey offers opportunities for medical treatments, and having a strong position in terms of health services and facilities to compete globally (Tenth Development Plan of Turkey, 2018). The medical tourism market reports indicate that Turkey is among the most preferred medical tourism destinations.

Medical tourism service offering requires the involvement of multiple parties from the service network. The medical tourism service supply chain (MTSSC) is a network of multiple businesses and people that plan medical services, supply necessary resources, deliver medical tourism services and manage information and financial flows between the service providers and the patients (Ferrer \& Medhekar, 2012). MTSSC is also a special subcategory of tourism supply chains that includes transportation, insurance, and accommodation providers, medicine and medical suppliers, and medical institutions (Lee \& Fernando, 2015). We define MTSSC as a network of service providers rendering services to medical tourists under the direction and control of an assistance company. Accordingly, MTSSC members include assistance companies, medical service providers, accommodation providers, tour services providers, flight ticket providers, transportation/transfer service providers, translation service providers, insurance companies and visa providers. A well-functioning MTSSC enables medical tourists to take advantage of faster, costefficient, high quality medical treatment opportunities with the benefits of traveling abroad and discovering new countries and locations.

A review of the current research on medical tourism via Scopus database reveals that most of the studies have focused on creating demand for medical healthcare (Ferrer \& Medhekar, 2012, Tang \& Abdullah, 2018), and only a few studies have explored the medical tourism supply chain as a whole (Lee \& Fernando, 2015). The fact that there are only a few studies with recent publication dates suggests that the research area is in emergence stage, where the focus of research efforts is on concept and theory building (Kuhn 1962; Sterman 1982). Accordingly, this study seeks to develop a conceptual model of MTSSC, the need for which has been emphasized in recent studies by Fernando and Lee (2015) and Lee and Fernando (2015) and define its business processes. In this study, triangulation (Denzin, 1978; Flick, 2004) was applied to develop and validate the suggested model and process definitions. It makes use of literature review, in-depth interviews, and expert evaluations. The theoretical framework of the proposed model is developed based on the relevant literature. During the in-depth interviews, the company 
representatives reviewed and discussed the initial model, and provided practical information about their operations and collaborations in terms of supply chain management. The experts' feedback was used to refine and finalize the model. Subsequently, the proposed model was presented at the 8th International Health Tourism Congress to healthcare management academicians and business authorities, and their opinions were collected regarding the trustworthiness of the model and process definitions. The feedback from experts revealed that although the proposed model has the desired MTSSC structure, there is a second version of the model used in practice, where assistance companies deal with the medical services, and travel agencies with the tourism-related services.

In the following sections of the paper, the methodology followed in the paper is explained. Accordingly, the MTSSC members are identified, and the medical tourism service flow is presented. Then, the proposed MTSSC conceptual model and the definitions of MTSSC business processes are provided. Next, the evaluations of experts on the concept and content of the proposed model and definitions are discussed. Finally, research findings, managerial implications, limitations, and future research directions are presented in the conclusion section.

\section{Methodology}

This study uses triangulation (Flick, 1992; Flick, 2004) to gain a deeper understanding of the MTSSC concept and to develop a conceptual model of MTSSC. Triangulation means examining a research topic using at least two different methodologies or from at least two different perspectives (Denzin, 1978; Flick, 2004). Reliance on mixed-methods allows the weakness of any single method to be canceled out by the strengths of the others (Bryman \& Bell, 2011). Triangulation is used to ensure research quality, to generalize discoveries and to extend domain knowledge (Flick, 2004). The four ways that triangulation can be used in the validation of qualitative research are data triangulation, investigator triangulation, theory triangulation, and methodological triangulation (Denzin, 1978). In this study, we employed multiple methods of investigation and multiple sources of data to refine and corroborate our model. Figure 1 illustrates the triangulation process used in this study.

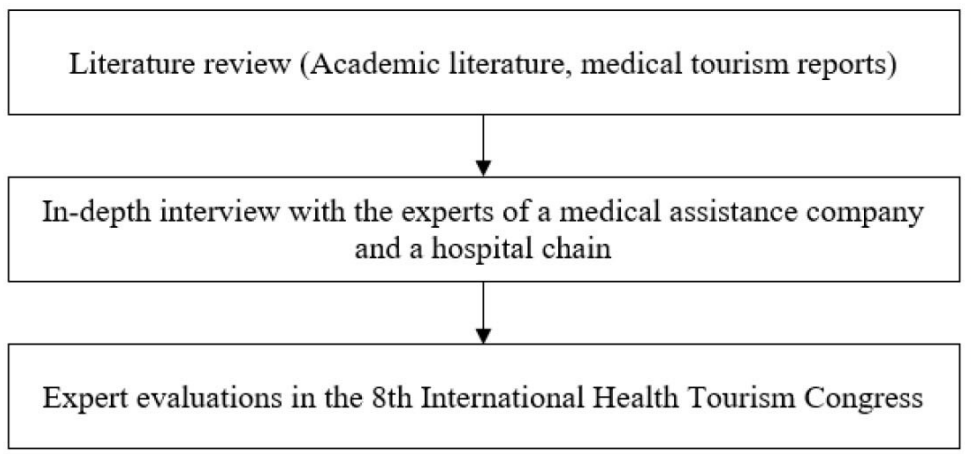

Figure 1. The triangulation process used in this study

\subsection{Literature Review}

A literature review is a survey and summary of the complete and current state of knowledge on a certain research topic from any collection of materials. There are a number of methods to conduct a literature review, which can be broadly categorized as the traditional narrative review, systematic quantitative review, and meta-analysis (Yang, Khoo-Lattimore \& Arcodia, 2017). This study conducts a traditional narrative review, where findings from prior studies are discussed, synthesized and quantified to demonstrate patterns, in a less rigid way, due to the small number of academic papers on the MTSSC. Also, this kind of literature review allows researchers to create conceptual models by synthesizing prior studies.

In order to make a broad search of the studies on MTSSC, the Scopus database that covers the well-known publishers such as Elsevier, Emerald, IEEE, Springer, Sage, Taylor \& Francis, Wiley-Blackwell was used. A Scopus search with the search words "medical tourism" in title-abstract-keywords, and "supply chain" in all text (Search term: (TITLE-ABS-KEY ( "medical tourism" ) AND ALL ( "supply chain" ))) resulted in 54 studies published 
between 2012 and 2020, after eliminating the irrelevant studies 51 of them remained. The papers published both in a proceedings book of a conference and in a journal with the same title were counted a single publication in the elimination process. Moreover, because of the defined keywords, the results involved medical-incentive papers having no or very minor tourism side, and they were eliminated as well. The current studies are mainly about the factors affecting medical tourism demand (Lin, Lee \& Huang. 2009; Ferrer \& Medhekar, 2012, Johnson \& Garman, 2015; Loh, 2015; Vetitnev, Kopyirin \& Kiseleva, 2016; Tang \& Lau, 2017; Tang \& Abdullah, 2018; Loh \& Triplett, 2019; Nilashi, Samad, Manaf, Ahmadi, Rashid, Munshi et al., 2019; Arulmozhi, Praveenkumar, Vinayagamoorthi, 2019; Al-Talabani, Kilic, Ozturen \& Qasim, 2019; Sedianingsih, Ratnasari, Prasetyo \& Hendarjatno, 2019), MTSSC management principles such as coordination, collaboration, information exchange and integration (Fernando \& Lee, 2015; Lee \& Fernando, 2015; Perkumiene, Vienažindiene \& Švagždiene, 2019; Cho \& Lee, 2019; KaradayiUsta \& Serdarasan, 2019), perceived MTSSC quality (Debata, Patnaik \& Mahapatra, 2012; Rahman 2019; Mohd Isa, Lim \& Chin, 2019; Sadeh \& Garkaz, 2019), benefits and risks of medical travel (Kumar et al., 2012), partnership quality between health institutions and travel agencies (Lin, 2014), and supply chain network modelling (Ahmadimanesh, Paydar \& Asadi-Gangraj, 2019).

Other than peer reviewed literature, we have reviewed a wide variety of data sources, including other academic sources such as books, working papers and conference papers, as well as reports and documents published by medical service providers', Turkish Ministry of Health and Turkish Healthcare Travel Council, in order to gain a deeper understanding of the MTSSC concept, its members, their processes and their relationships. The output of this phase was the initial version of the conceptual model with definitions of supply chain processes.

\subsection{In-Depth Interviews}

An interview aims to gather descriptions of the interviewee's worldview with respect to the interpretation of the meaning of the described phenomena (Kvale, 1983). In-depth interviews are described as a form of conversation with a purpose (Legard, Keegan \& Ward, 2003). It is a qualitative research technique that allows the interviewee to express his/her ideas on specific issues and requires only a small group of interviewees (Boyce \& Neale, 2006). It is important that the in-depth interviewer is well-trained for both providing detailed information and for making the interviewee comfortable. Body language, curiosity, ability to introduce subjects for evaluation, communication competence are the other essential features of an interviewer (Legard et al., 2003; Boyce \& Neale, 2006).

We have conducted in-depth interviews with the operation manager of an assistance company and with the international marketing manager of a hospital chain both headquartered in Turkey to gather detailed information on the current supply chain practices regarding medical tourism services and discuss the initial version of the model. The assistant company and the hospital chain are highly recognized global facilitators representing Turkey in the international medical tourism market by attracting medical tourists and by arranging agreements that ensure continuous cooperation with other countries' facilitators. The interviewed parties represent the must-have service providers and key enablers for a medical tourism service. The interviewed representatives are able to provide the points of view of the other supply chain members due the scope of their operations, thus, we have found consulting them enough to discuss the initial version of our model.

The first author acted as the interviewer and was able to manage the interview process effectively and obtain all the necessary information. Semi-structured open-ended questions were asked to the interviewees. As experienced sector practitioners, the experts provided information about their collaborations, suppliers, customers and business processes, as well as insights into the suggested model, which helped us to refine and finalize the proposed model.

\subsection{Expert Evaluations}

Operating in a dynamic and uncertain environment, MTSSC is a complex network of businesses, with a high number and variety of processes, and interdependencies between these. Thus, understanding and examining it in its entirety is not straightforward, and empirical support to do so is not often available. Expert evaluation is a possible way of dealing with this problem, where a panel of experts is used to elicit judgments on issues that are complex and subjective (Garrod \& Fyall, 2005). 
The proposed conceptual model was presented to healthcare management academicians and business authorities at the 8th International Health Tourism Congress. The experts were selected on the basis of their knowledge and expertise, which put them in a privileged epistemic position with regard to understanding the MTSSC. During the presentation, the participants were free to comment or ask questions, which contributed to a better understanding of the topic and allowed the participants to make their evaluations on the basis of informed reflection. After the presentation, an expert evaluation form consisting of evaluative statements and open-ended questions on the definitions, benefits, and limitations of the MTSSC model and its processes were distributed to the participants. This was followed by an interactive discussion guided by the first author. 10 academicians, 4 government representatives, 8 assistance company authorities and 8 healthcare service provider executives were evaluated the study during the presentation (see Table 1).

\begin{tabular}{|c|c|}
\hline Expert title & Institution \\
\hline Faculty Member, Healthcare Management & AA University \\
\hline Faculty Member, Tourism Management & BB University \\
\hline Faculty Member, Public Health Department & CC University \\
\hline Faculty Member, Healthcare Management & DD University \\
\hline Faculty Member, Healthcare Management & EE University \\
\hline Faculty Member, Business Administration & FF University \\
\hline Faculty Member, Business Administration & GG University \\
\hline Faculty Member, Healthcare Management & HH University \\
\hline Faculty Member, Healthcare Management & JJ University \\
\hline Faculty Member, Health Sciences & KK University \\
\hline Internal Control Unit Representative & LL City Board of Health \\
\hline Health Tourism Coordinator & Ministry of Family and Social Policies \\
\hline Health Tourism Specialist & Ministry of Family and Social Policies \\
\hline Health Tourism Specialist & Ministry of Family and Social Policies \\
\hline Project Manager & Medical Tourism Consultancy Co. \\
\hline Finance Director & MM Health and Welfare Foundation \\
\hline General manager & NN Medical Tourism Co. \\
\hline Sales and business development manager & PP Travel - Health Tourism Agency \\
\hline Owner & QQ Healthcare Services \\
\hline Founder & RR Healthcare Services \\
\hline Managing partner & SS Healthcare Services \\
\hline General manager & TTT Assistance Co. \\
\hline Int. business development ass. manager & VV Eye Care hospital \\
\hline Marketing manager & YY Hospital Group \\
\hline Assistant director & YY Hospital Group \\
\hline Int. marketing \& business dev. Manager & ZZ Hospital Group \\
\hline Business development coordinator & AZ Healthcare Group \\
\hline International marketing manager & BZ Private Hospital \\
\hline International relationship director & CZ University Hospital \\
\hline Managerial coordinator & DZ Medical Center \\
\hline
\end{tabular}

Table 1. Expert profiles 
The feedback and responses were used to test and confirm the conceptual model. The expert evaluation served more as a refinement and justification for the proposed model. Additionally, based on the expert feedback a second version of the model, which is more common in practice was revealed.

As a result, triangulation enabled us to gain a better insight into the MTSSC and generate the conceptual model, where literature review, in-depth interview, and expert evaluation were used to gather data from academic literature and practice. Furthermore, triangulation helped us define the medical tourism experience and medical tourism service supply chain members, as described in the following section.

\section{A Conceptual Model of Medical Tourism Service Supply Chain}

The conceptual model of MTSSC suggested in this paper uses ideas from the medical tourism supply chain literature (Lee \& Fernando, 2015; Connell, 2006; Glinos et al., 2006; Ferrer \& Medhekar, 2012; Fernando \& Lee, 2015; Debata, Patnaik \& Mahapatra, 2012; Kumar et al., 2012; Lin, 2014), service supply chain models suggested by Baltacioglu, Ada Kaplan and Yurt (2007) and Ellram, Tate and Billington (2004), supply chain business processes literature (Lambert \& Enz, 2017; Lambert \& Cooper, 2000; Lambert, 2009; Bolumole, Knemeyer \& Lambert, 2003; Croxton, García-Dastugue, Lambert \& Rogers, 2001; Croxton, Lambert, García-Dastugue \& Rogers, 2002; Croxton, 2003; Goldsby \& Garcia-Dastugue, 2003; Lambert \& Schwieterman, 2012; Rogers, Lambert, Croxton, García-Dastugue, 2002; Rogers, Lambert \& Knemeyer, 2004), and service operations management research and practice (Fitzsimmons \& Fitzsimmons, 2011; Johnston, Clark \& Shulver, 2012; Haksever \& Render, 2013). The model was then refined and elaborated upon based on the in-depth interviews with executives of an assistance company and a hospital chain. In line with our definition of the MTSSC - as a network of service providers rendering services to medical tourists under the direction and control of an assistance company-, the proposed model demonstrates the assistance company as the governor of all service processes (see Figure 2). The proposed model uses a nested process structure rather than a one-dimensional supply chain model to emphasize the need for intense coordination and collaboration. In the model, there are no strict borders or limits between supply chain member activities, instead, members are expected to conduct joint business activities collaboratively.

The MTSSC members are identified based on the literature review and the interviews with the executives of the assistance company and the hospital chain. Furthermore, the congress participants were asked to confirm these supply chain members. The medical tourism service supply chain members and their responsibilities are listed as follows:

- Patient: makes a request to receive treatment, fills in forms, gives informed consent, provides required tests and reports, acts in compliance with the treatment plans, makes payment.

- Assistance company: examines patient applications, offers medical advisory, asks patients for tests, analyses, and examination reports, translates these reports into the official language of the host country, informs the patients about costs and treatment processes, offers healthcare institution options, plans appointments at pre-operation medical evaluations, collects payments, provides medical escorts, keeps in touch with patients through the $24 / 7$ alert center service, coordinates with other service providers.

- Medical service provider: arranges the pre-operation medical evaluation, informs the patient, takes patients' consent, provides treatment, provides reports, prescriptions, and fit-to-fly documentation, and produces insurance-related documents.

- Ambulance/transfer/transportation services provider: picks up medical tourists from the airport and transfers them to a hotel or a hospital, and offers ambulance services.

- Accommodation services provider: accommodates medical tourists for specific dates.

- Flight ticket services provider: books flights, completes invoicing.

- Translation services provider: reserves a multilingual translator at the destination.

- Tourist activity/tour services provider: provides medical tourists with package/standard or individual tours, guides and escorts tourist at tourist sites.

- Visa services provider: handles the entire visa arrangement process.

- Insurance services provider: deals with the entire insurance and payment process. 
The conceptual model presented in Figure 2 proposes that the medical tourism process is triggered by the patient's application, where the assistance company supports and guides the patient, and medical treatment services are obtained. Along with the medical services, the medical tourism service includes other services, such as accommodation, transportation, flight ticket purchase, tourist activities, visa, translation, and insurance. All services are provided simultaneously, as needed, under the governance of the assistance company. The model also shows the MTSSC business processes and the members who take part in their execution in order to ensure the smooth flow of the services. The conceptual model identifies seven MTSSC business processes that are the core of supply chain management activities and that provide a unique value to the patient. These are service design (SD), service recovery management (SReM), customer relationship management (CRM), supplier relationship management (SRM), demand management (DM), capacity and resource management (CaRM), and service delivery management (SDM). Along with the process flows there is a need to manage information and financial flows throughout the supply chain. Managing information flows is especially important since IT supports the efficient flow of all processes and improves accuracy in service delivery, faster response, higher flexibility, and operational efficiency. In the following subsections, each business process is defined with a focus on the activities of medical tourist, assistance company and healthcare institution.

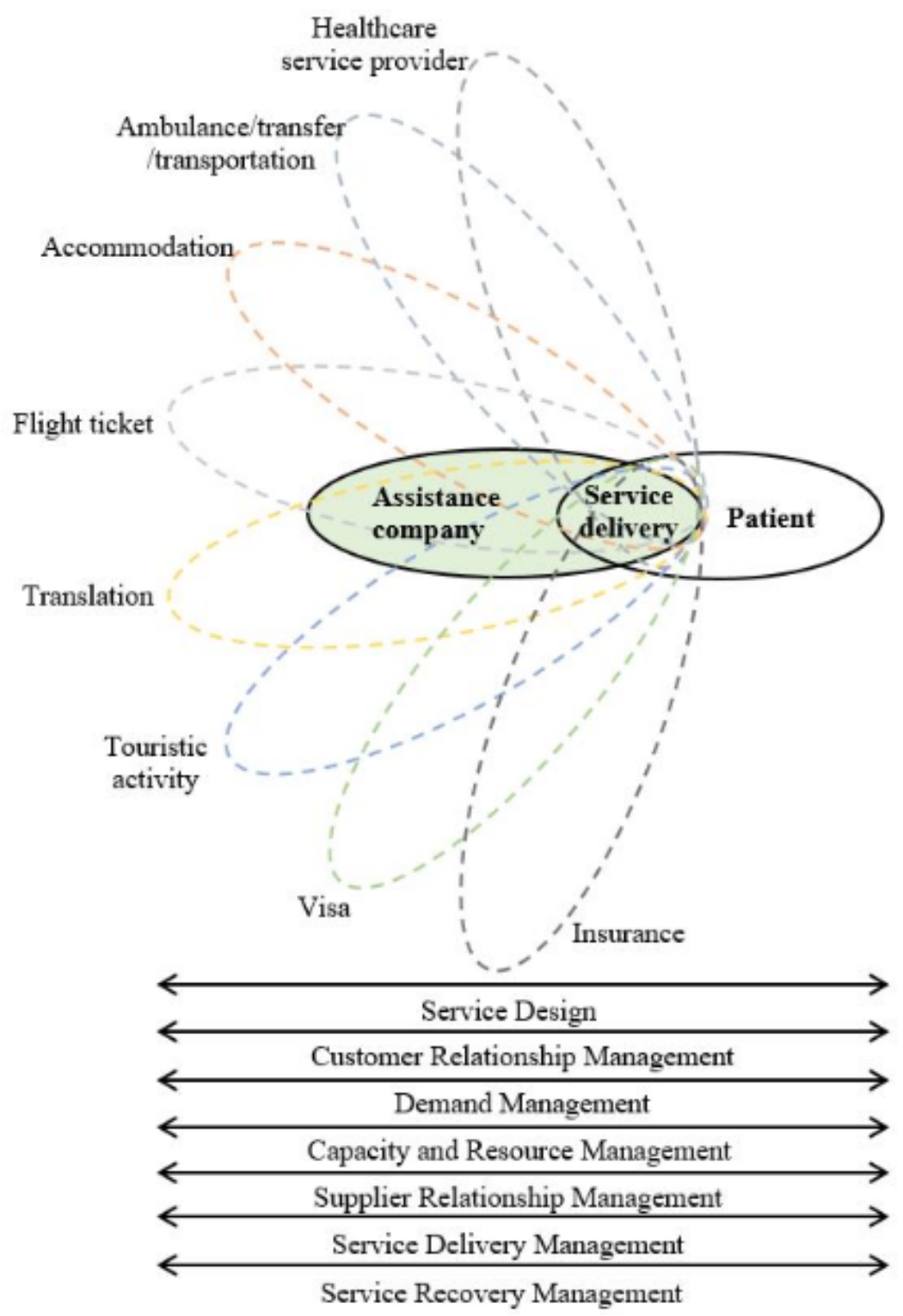

Figure 2. Proposed MTSSC model 


\subsection{Service Design}

SD is concerned with planning and organizing the capacity and resources, creating and improving processes, communication, and infrastructure as well as designing and enabling the physical elements of the service. In short, the SD process compasses all processes starting from idea generation to implementation (Goldstein, Johnston, Duffy \& Raod, 2002). To do this, service elements should be well defined and visualized in a proper way (Shostack, 1982). The concepts of the delivery system, facility design, location, service quality, capacity and demand planning, information and service encounter are essential elements of the design process (Fitzsimmons et al., 2011). All these elements must be unified to create a consistent and sustainable service. Service innovation is an important aspect of achieving this goal.

As a part of the SD process, medical tourism service delivery systems focus on the quality dimensions such as accessibility/convenience, treatment satisfaction, courtesy, physical environment features, technical quality of care competency, promptness, facility premises, and financial factors (Debata, Patnaik, Mahapatra \& Sree, 2015). Healthcare service quality (Chuang, Liu, Lu \& Lee, 2014, Abadi, Sahebi, Arab, Alavi \& Karachi, 2018), quality standards and assurance (Fernando \& Lee, 2015, Ajmera, 2017), partnership quality between service providers (Lin, 2014) are significant aspects in the design of medical tourism services. Medical tourists, having a culture and customs different from the host country, may require some changes to the way the medical services are delivered. For example, when hosting Muslim medical tourists, service providers need to accommodate Muslim patients' religious beliefs and faith (Iranmanesh, Moghavvemi, Zailani \& Hyun, 2018). Supplier delivery systems and internal delivery to departments (Kumar, Ozdamar \& Zhang, 2008) should be designed addressing these kinds of patient needs.

Location of a service facility is another concern in medical tourism SD. The location selection decision of a medical service provider should be made considering the distance between the hospitals and the location of other services, e.g. considering the transfer of medical tourists from airports (Kumar et al., 2008). The design of the medical facility with convenient parking and accessibility to the building with medical equipment is another important point (Pitt, Chotipanich, Issarasak, Mulholland \& Panupattanapong, 2016). When designing a medical service facility, the factors such as the size of the facility (Lin, 2014), meeting patients' expectations (Pitt et al., 2016), service provision steps, medical intervention process, facility functions (such as parking, hygiene, and catering), location of departments according to the flows, etc. are to be taken into consideration.

We define the SD process in MTSSC as a well-defined and structured service development process that is shaped in accordance with the needs and expectations of the patient in order to create a pleasing medical tourism experience. The first thing to achieve this is understanding the customer expectations, so that the answers to questions such as what the target market segment is, what the patients are willing to pay for, which capabilities and resources the providers need in order to fulfill the needs and expectations of the patients are provided. This way, the providers can design their service processes, plan their capacity and human resources and make sourcing decisions accordingly. Along with these, the providers also need to make decisions about the location of the facility, the ways to access the facility, and recruiting the right people.

\subsection{Customer Relationship Management}

CRM includes all processes focusing on the interface between the service provider and the customer (Chopra \& Meindl, 2004). The basic processes of the CRM are segmenting the customers, understanding and meeting the priorities of each segment, identifying opportunities to co-create value, developing profitable service propositions that match the requirements of the segment with the capabilities of the firm, customizing these service propositions according to customer needs, monitoring the plans and execution, and collaborating with other processes to guarantee the smooth flow of the process (Lambert, 2009).

With respect to CRM, medical tourism service literature focuses on customer satisfaction (Lee \& Fernando, 2015; Lin, 2014; Pitt et al, 2016; Rahman \& Zailani, 2017; Kumar \& Blair, 2013), customer care (Lunt, 2015), customer needs (Muljo \& Pardamean, 2013), bargaining power of the customer (Muljo \& Pardamean, 2013), customer-fitted services (Medhekar, Wong \& Hall, 2014). Ajmera (2017) emphasizes the importance of 'creating convenience for patients and developing and strengthening customer relationships'. Kumar and Blair (2013) draw attention to long term relationships between employees, suppliers, and customers as a contributor to success. 
Medical tourism literature considers information technologies and enhanced communication systems as a medium to attract medical tourists since these infrastructures can enable patients to reach medical centers/physicians in other countries (Genc, 2012). Presence in the internet and social media act as effective marketing tools by enhancing visibility. Additionally, infrastructures related to transportation and communication in a destination country are factors affecting the medical tourism demand (Chasapopoulos, den Butter \& Mihaylov, 2014; Adeola, Boso \& Evans, 2017; Ramos \& Rodrigues, 2013).

Consequently, the CRM in medical tourism focuses on the interface between the service providers and the medical tourist. It involves all the processes that make effort to create demand for medical tourism -including the marketing activities and making an actual sale to a medical tourist, make customizations in the service offering in accordance with the patients' needs and requirements, maintain a good communication and trust with the patients and inform them whenever needed throughout the medical procedure and afterwards, monitor the outcomes, receive feedback using questionnaires, face to face or telephone interviews, and report to ensure continuous improvement.

\subsection{Demand Management}

$\mathrm{DM}$ is about finding a balance between the customer requirements with supply chain capabilities via the processes of forecasting demand and aligning it with sourcing, production, and delivery capabilities (Croxton et al., 2002). Due to common characteristics of the services being intangible, inseparable and perishable, services cannot be inventoried for later use. Thus, in order to form a balance between customer demand and service delivery, the service provider needs to not only to generate demand for its services but also match the demand with its supply chain's service delivery capacity and capabilities (Ellram et al., 2004; Baltacioglu et al., 2007). The DM process covers gathering relevant data, generating forecasts, synchronizing and integrating demand plans with capacity plans throughout the supply chain (Croxton et al., 2002). While good relations and communication with customers are required in order to forecast the demand accurately, good relations and communication with suppliers are required to meet the actual demand.

Demand for medical tourism is defined as request for medical services, at a particular destination, at a given price and time (Medhekar \& Haq, 2015). An effective DM process requires an understanding of the overall medical tourism experience and an effective synchronization between supply chain partners (Medhekar \& Haq, 2015). Rahman and Zailani (2017) report trust as an important determinant in generating medical tourism demand. There are studies in medical tourism literature focusing on increasing demand for halal medical tourism services (Medhekar \& Haq, 2015; Rahman \& Zailani, 2017), and studying various host countries' demand patterns (Lin et al., 2009; Genc, 2012; Johnson \& Garman, 2015; Loh, 2015; Vetitnev, Kopyirin \& Kiseleva, 2016; Dang, Huang, Wang \& Nguyen, 2016; Tang \& Lau, 2017; Tang \& Abdullah, 2018).

We define DM as a process that plans medical tourism demand in alignment with the service capacity of all parties involved in the medical tourism service delivery. It includes gathering data from the market (historical sales and other factors affecting the demand behavior), forecasting the demand and generating a collaborative demand plan by taking the impact of the efforts made in the CRM process into account, synchronizing and adapting the capacity of all supply chain members with the demand plan, and creating the ability to respond to changes in demand and increasing flexibility.

\subsection{Capacity and Resource Management}

CaRM involves service providers' activities to balance capacity and demand for their services (Murray \& Berwick, 2003; Xu, Prats \& Delahaye, 2018, Sanden, Everwijn, Rouwette \& Gubbels, 2005). Back-stage operations and support processes that are typical for a service delivery system are performed in this context. The processes included are employee and job scheduling, material requirements planning, facility and equipment scheduling, and outsourcing planning (Ellram et al., 2004; Baltacioglu et al., 2007).

CaRM includes balancing the capacity and resources with the demand plan generated during the DM process. In order to integrate capacity and demand with service operations, there are strategies to follow: matching the patient demand and availability of the health professionals, preventing backlogs, reducing the number of appointment 
types, developing contingency plans, reducing and shaping the demand for visits, increasing the effective supply (especially the bottleneck resources) (Murray \& Berwick, 2003)

Service capacity is dependent on time, labor, equipment and facility constraints (Fitzsimmons \& Fitzsimmons, 2011; Wilson, Zeithaml, Bitner \& Gremler, 2016). Medical service capacity includes the number of appointment slots per day for each health professional (Murray \& Berwick, 2003) and number of beds or medical equipment in a hospital. The maximum number of patients to be handled is limited by the capacity of a hospital serving medical tourists (Malairajan, Ganesh, Qureshi, Anbuudayasankar \& Lee, 2012). For example, a hospital has capacities for medical staff, specialist surgeons and physicians, number of beds and medical material resources and an awaiting list of patients (Medhekar et al., 2014). Utilizing cutting-edge technological medical equipment, and following the latest technological innovations improves service capacity and enables enhanced SDM.

Human resource management (Abadi et al., 2018; Jain \& Ajmera, 2018; Muljo \& Pardamean, 2013; Rahman \& Zailani, 2017), resource dependence (Lin, 2014), resource allocation (Malairajan et al., 2012), operational performance measurement (Lin, 2014; Kim, 2017; Rahman \& Zailani, 2017), demand and capacity integration (Murray \& Berwick, 2003; Xu et al., 2018; Sanden et al., 2005), and capacity planning (Murray \& Berwick, 2003; Farmer, Hosek \& Adamson, 2016; Wirtz, 2016; Tripathi, Elneil \& Romanzi, 2018) are some of the topics discussed in the literature within the context of medical tourism service resource management. Human resource planning is critical due to the high level of human participation to deliver services in order to guarantee satisfied patients (Rahman \& Zailani, 2017).

In brief, CaRM is a process of strategic, tactic and operational planning to balance and manage capacity and demand via employee and job scheduling, material requirements planning, facility and equipment scheduling, and outsourcing planning.

\subsection{Supplier Relationship Management}

SRM focuses on the interaction between the service provider and its suppliers (Chopra \& Meindl, 2004). The SRM process provides the structure for how relationships with suppliers will be developed, managed and implemented (Lambert \& Schwieterman, 2012). It consists of product/service development, sourcing, supply planning, and purchasing, supplier evaluation (Baltacioglu et al., 2007), and all the communication between the company and its current and future suppliers (Chopra \& Meindl, 2004).

The typical suppliers in an MTSSC are medical service providers, assistance companies providing medical consultancy, tour services providers offering tourist activities, accommodation providers, flight ticket suppliers, transportation/transfer service providers, translation service providers, and insurance and visa providers (Medhekar \& Haq, 2015; Rahman \& Zailani, 2017). In a MTSSC, members conduct business activities collaboratively and act as providers to each other. The relationships with the suppliers in a medical tourism service supply chain are governed via service level agreements between the customers and the suppliers. Negotiating with potential suppliers, procurement, and performance evaluation are some of the SRM business processes within the medical tourism service. Studies also mention the need for coordinating the interrelated activities of multiple service providers (Rahman \& Zailani, 2017) especially in terms of CaRM.

We define SRM in medical tourism as a process that structures, plans, and executes the relationships between the service providers and the assistance company. It involves negotiations with suppliers, designing and implementing service level agreements, procurement of services and materials, performance evaluation of suppliers and all collaborative activities. Since service suppliers in a medical supply chain are in direct contact with the medical tourist, alignment of goals along with high levels of trust and communication between providers are necessary for success.

\subsection{Service Delivery Management}

SDM focuses on the interaction between the service provider and the customer at the same time and place with the purpose of service delivery. It is accepted as the main function of the service supply chain (Ellram et al., 2004; Baltacioglu et al., 2007). According to Ellram et al. (2004), SDM from the service provider's perspective is about making promises to the customers, enabling services and meeting these promises, while from the customer side, it is about clarifying the expectations, enabling the service provider to manage its operations, monitoring the 
compliance, and providing feedback, and payment. Human resources are significant in both SDM and CaRM, since the human involvement plays a vital role in service delivery.

In terms of service delivery, the literature on medical tourism mainly emphasizes the interaction between the health professional and the patient (Glasner, 2009; Kumar et al., 2012). Service providers should understand the patients' requests, and perform appropriate medical procedures. Furthermore, a healthcare professional should inform patients during a medical intervention about the examination process in order to comfort the patients. Muslim friendly medical tourism is a special case, in which understanding Islamic cultural sensitivities is an essential point for SDM and CaRM (Medhekar \& Haq, 2015). For instance, Muslim female patients request female health professionals (Iranmanesh et al., 2018).

We define SDM as a process that manages all activities that take place between the service provider and the patient at the same time and place during the service delivery. It includes the patient to be clear about their needs and expectations and the provider to understand and meet these expectations by utilizing its available skills, capacity, and resources. It also requires the patient to adhere to the recommended course of treatment and to provide feedback.

\subsection{Service Recovery Management}

SReM is defined as the activities to deal with the customer dissatisfaction in order to prevent customer loss. It is also considered as "doing the right thing at the second chance" or "the second chance for the first impression". Service recovery process steps are essentially understanding the case, evaluating the situation and options, implementing a solution, monitoring and reporting (Bolumole et al., 2003). A well-managed service recovery activity provides an opportunity to satisfy the customer and to gain trust and loyalty (Cengiz, Akdu \& Bostan, 2015). In other words, service recovery turns the lost customer into a well-satisfied permanent customer (Fitzsimmons \& Fitzsimmons, 2011). The frequently used ways of recovery are listening, apologizing, recovering in a fair way, and conciliation (Goldstein et al., 2002).

Since medical tourism is at the intersection of tourism and healthcare activities, the literature research for service recovery covered these service industries as well. A service failure in the hospitality industry can occur in arrival, billing, departure, guest room, food services, staff or other services (Wu, Qomariyah, Sa \& Liao, 2018). Service recovery can be performed by apology, explanation, immediate solution, free additional service, upgrade/change, discount, managerial intervention, or replacement (Wu et al., 2018). Service recovery performance in healthcare services is affected by fairness, commitment, workplace support (Nadiri \& Tanova, 2016), cultural competence, self-management, social capacity, organizational recovery system and recovery self-efficacy (McQuilken, Robertson, Abbas \& Polonsky, 2018). Furthermore, error management training is an option to improve employees' service recovery performance (Yao, Wang, Yu \& Guchait, 2019). These are all applicable to service recovery in medical tourism services. Um and Kim (2018) reveals that a stimulus (informational, interpersonal, procedural or outcome failures) can trigger dissatisfaction of a medical tourist resulting in switching the service provider, complaining, negative word of mouth, or inertia as a passive response.

In brief, we define SReM as a process that deals with the medical tourist's dissatisfaction with the provided services, in particular with medical services, in order to get a second chance at satisfying the needs and expectations of the medical tourist. The first step of the SReM process is understanding the source of the dissatisfaction. In case the failure is related to tourism services the recovery can be executed in terms of apology, free additional service, upgrade/change, discounts, or payback. However, these recovery options are not suitable for medical service failure, then the medical procedure needs to be repeated free of all charges. After implementing the recovery solution, the case should be monitored and reported.

\section{Expert Evaluations of the Proposed Model}

Expert evaluation is an effective way to elicit judgments on complex and subjective models such as the MTSSC model proposed in this paper. The proposed model was presented to healthcare management academicians and business authorities at the 8th International Health Tourism Congress. The participants were asked to provide feedback on the structure of the model, members of the MTSSC, the business process definitions, and members involved in each process. The feedback was gathered via an interactive discussion guided by the first author and a 
form consisting of evaluative statements and open-ended questions. The expert evaluations made it possible to validate our model and definitions.

The experts agreed on and confirmed the proposed structure and the members. They mentioned other parties such as home care service providers, information technology consulting companies and law offices specialized in health law to be added to the list of service providers. However, since the suggested supply chain members are not considered immediate parties, they were not included in our conceptual model.

Experts draw attention to a second version of the proposed model that is more common in practice as illustrated in Figure 3. The experts indicated that the "medical consultancy" and the "travel agency" are two separate lines of business, and this type of structure is more frequent in the market. In this second model, the assistance company provides the medical services for the patients, and all the tourism-related services are supplied by travel agencies (see Figure 3). The experts pointed out that this structure is preferred by the companies since it allows to focus on their own competencies. Moreover, the services that a travel agency provides are mainly optional and can be handled by the patients themselves, or the assistance companies can direct patients to a travel agency upon request. On the other hand, the experts indicated that the patients prefer the form of the initial version of the model, since they only want to concentrate on their treatment in a foreign country, instead of trying to answer challenging questions such as "how will I arrange the travel and touristic activities?" or "will I have trouble receiving a visa or making insurance payments?". In other words, since traveling abroad is stressful, patients want a single company to deal with everything related to both treatment and travel. Thus, all services being managed via a single intermediary is preferred by patients, mainly for its convenience.

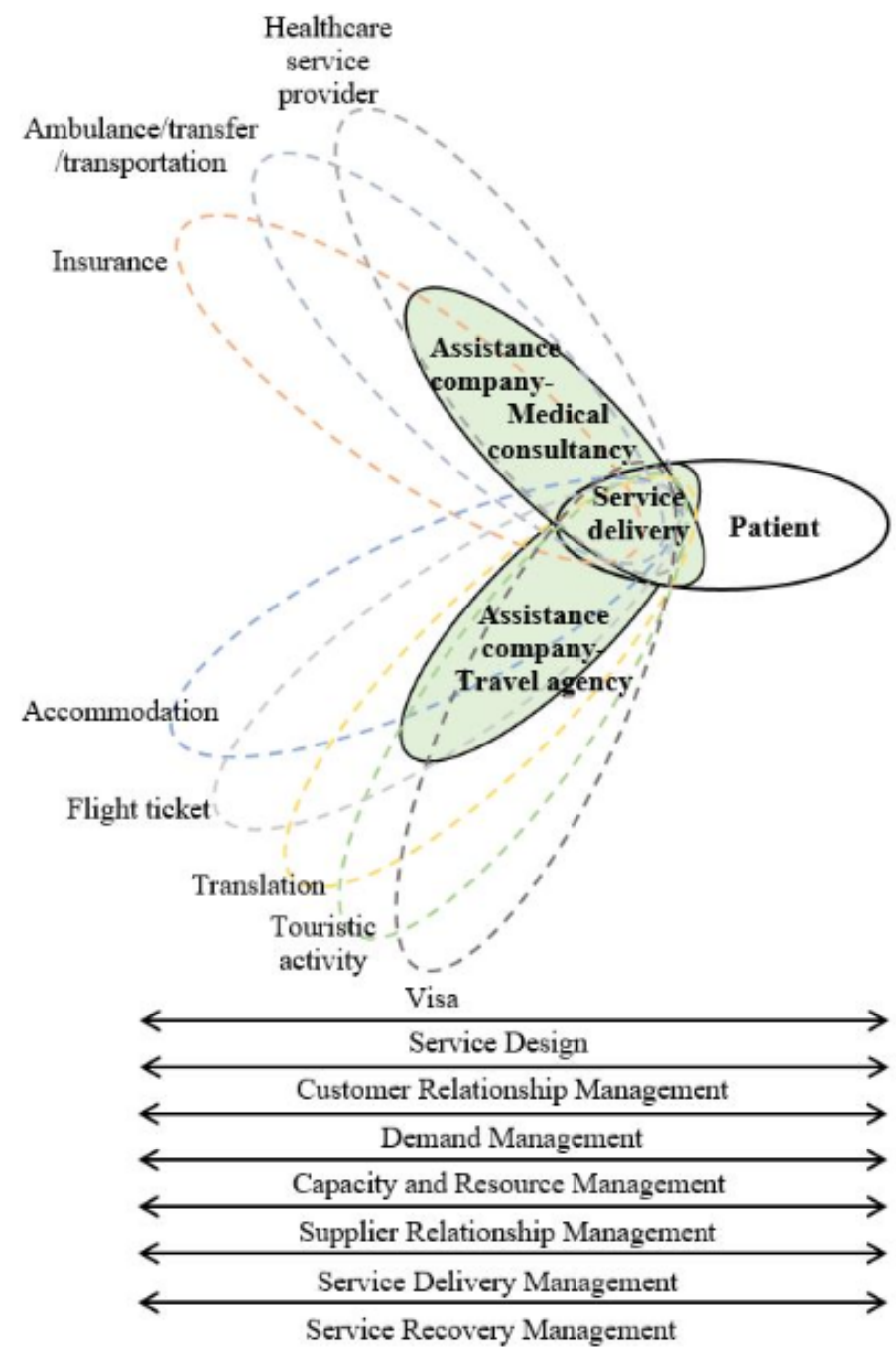

Figure 3. Second version of the proposed MTSSC model 
The experts approved the business process definitions and the members involved in each process. Additionally, they emphasized the importance of the following issues for each business process:

- SD: Patients' and patient relatives' feedback about medical tourism, nursing, and rehabilitation service experiences as well as their demands and expectations should be taken into consideration when designing the medical tourism service.

- CRM: Social and cultural support must be provided considering the medical tourists' requests. Additionally, qualifications (e.g. multilingual) of medical professionals and patient assistants should be developed to improve customer experience. Finally, the marketing efforts would be effective in forming an awareness about medical tourism opportunities and attracting medical tourists to the destination country.

- DM: The characteristics of services should be considered when forecasting demand and planning capacity. In order to manage demand more effectively, data collection, processing, analysis, and evaluation should be well defined and structured.

- CaRM: Planning the exact times of appointments, assessing the health professional to the slots of visits, and arranging operation rooms of a healthcare facility, and focusing on resource and capacity management for aftercare services are of importance in CaRM. The activities should be managed in coordination to maintain business continuity.

- $\quad$ SRM: The suppliers should provide assurance on the quality of their services and products in SRM. Apart from that, the experts mentioned the importance of SRM since any failure in sourcing at the right time and place, any problems in coordination and communication with suppliers lead to dissatisfaction with the service.

- SDM: In order to provide assurance to the medical tourists that they are receiving the right treatment, healthcare professionals should inform patients and their relatives at each phase of the service operation. Especially, patient representatives should provide guidance to the patient, and service providers should avoid treating the patient as a cash cow. According to the experts, the major SDM challenge is that the focus of the business partners remains on "saving the day" instead of making plans and developing processes to improve the service experience.

- SReM: The service recovery should consider the characteristics of services and the problems these characteristics can cause. For instance, services are instantaneous and some parts of the service experience can only be evaluated after a while. Hence, SReM is not only for immediate service failures but should consider a longer span of time, especially for medical services.

\section{Conclusion and Further Research}

The success of medical tourism services requires the participation of multiple parties and relies on the coordination and joint activity of the involved parties. Thus, taking a supply chain perspective to medical tourism service would be beneficial. The medical tourism supply chain literature mentions the necessity of a conceptual framework to visualize and demonstrate the structure and members of the supply chain (Lee \& Fernando, 2015). Accordingly, this study seeks to develop a conceptual model of the MTSSC and define the business processes to be fulfilled for business continuity. It employs a triangulation approach using multiple methods and sources of data to build and validate the conceptual model and the process definitions. It makes use of literature review, in-depth interviews, and expert evaluations.

The literature review yielded the initial version of the proposed MTSSC model and process definitions, while the in-depth interviews with the executives of two separate medical service providers supplied detailed information on current supply chain practices regarding medical tourism services, and produced the proposed conceptual MTSSC model. Finally, expert evaluations refined and finalized the MTSSC model and business process definitions, and also revealed a second version of the MTSSC model.

The proposed model uses a nested process structure rather than a one-dimensional supply chain model to emphasize the need for intense coordination and collaboration in services. In the model, the assistance company maintains an intermediary role between the patient and the service providers (medical treatment, transportation, 
accommodation, touristic activities, translation, insurance, and visa). Additionally, the conceptual model identifies seven MTSSC business processes that are the core of supply chain management activities and that provide a unique value to the patient: service design, service recovery management, customer relationship management, supplier relationship management, demand management, capacity and resource management, and service delivery management. The proposed model also defines the boundaries of these business processes, i.e. defines which supply chain member/s is/are responsible for which business processes. The expert evaluations revealed a second version of the model, where the medical consultancy and travel agency services are detached. This structure is widely observed in the market since healthcare services and tourism and travel-related services are two separate lines of business and companies prefer to foster their existing competencies.

Lincoln and Guba (1985) and Guba and Lincoln (1994) propose that quality, reliability, and validity of qualitative research can be established by trustworthiness which is made up of four criteria: credibility, transferability, dependability, confirmability (Bryman \& Bell, 2011). Credibility, which corresponds to internal validity was ensured by triangulation. Transferability as a means of external validity was ensured by expert evaluations. Dependability which corresponds to reliability was ensured by following structured research steps and procedures such as complete records of all research phases, problem formulation, expert selection, fieldwork and interview notes, etc. Confirmability as a means of objectivity was ensured by maintaining researcher impartiality in all steps of the study. Additionally, this study performed an exhaustive expert selection process in order to make sure that expert judgments are reliable and unbiased. In brief, by using multiple methods of investigation and multiple sources of data to study the phenomenon of our interest, and having results that show mutual confirmation, we believe that our model and definitions are trustworthy.

The proposed conceptual model is built upon the theories and practice of medical tourism services, supply chain management, and service operations management. This study contributes to the theory of medical tourism services management by explaining the MTSSC concepts and business processes and extends existing knowledge.

The major scientific, managerial and practical implications of a conceptual model of medical tourism services supply chain and business process definitions are:

- Responding to the call of Fernando and Lee, (2015) for a medical tourism supply chain framework, this study provides a MTSSC framework and defines the relevant business processes for the first time.

- The model provides a better understanding of the MTSSC structure and processes, and a recognition of the MTSSC members. The definitions of the processes are shaped considering the members' activities, therefore, each member will have an idea where and when they have a role in the service design and delivery in practice. This understanding makes it possible to be prepared and internally organized for each supply chain member. Furthermore, a supply chain practitioner can use the definitions to understand the flow of the MTSSC processes.

- A better understanding of the system leads to better process development and control. The supply chain members may shape their own organizations internally and supply chain-wise by considering this conceptual model. In other words, any supply chain member would know where it stands in the bigger picture, develop its business processes, organize its operations and working environment accordingly, and collaborate with its business partners effectively.

- The model acts as a basis for outsourcing and business collaboration decisions. In this increasingly complex and resource intensive service business, outsourcing and collaborating with partners would be more advantageous for business continuity. As expected, supply chain members in medical tourism want to focus on their own competencies for business excellence. For instance, a medical consultancy company prefers only to focus on medical cases instead of additionally providing airport transfer or touristic services, thus it outsources these services and collaborates with service suppliers that are more competent in those areas.

It is possible to say that the choice of experts and that not all supply chain members are represented in the interviews are limitations of this research in terms of generalizability. However, experts are effective and convenient to receive accurate feedback in comparison to other data gathering methods especially in studies that 
define the concepts as well as develop frameworks such as this one. All experts are operating in Turkey, which may influence the results, yet medical tourism services in Turkey had a great breakthrough and investments have been made in recent years making Turkey one of the leading destinations in medical tourism and a provider of good practices. Additionally, this study uses a triangulated approach in order to overcome these limitations.

The limitations of this study also serves as a future research direction. Studying the proposed model by including wider representation along the actors covering a variety of countries might be possible future studies.

Further research should emphasize service supply chain processes and their interactions in a detailed manner. A process reference framework can be developed to implement the model emphasizing the collaborative aspects of medical tourism service supply chain flows. Best practices can be investigated and reported to address questions such as: Which tools and techniques can be used in order to conduct the processes? What kinds of service business units can utilize and improve the applicability of the processes? Each service supply chain process can be viewed as a new topic of study by determining the tools, activities, and business units. Case study method can be used to establish higher credibility and generalizability of the proposed model.

\section{Acknowledgements}

We gratefully acknowledge comments from the participants of the 8th International Health Tourism Congress and the executives of Marm Assistance and Hospitadent.

\section{Declaration of Conflicting Interests}

The authors declared no potential conflicts of interest with respect to the research, authorship, and/or publication of this article.

\section{Funding}

The authors received no financial support for the research, authorship, and/or publication of this article.

\section{References}

Abadi, F.A., Sahebi, I.G., Arab, A., Alavi, A., \& Karachi, H. (2018). Application of best-worst method in evaluation of medical tourism development strategy. Decision Science Letters, 7, 77-86. https://doi.org/10.5267/j.dsl.2017.4.002

Adeola, O., Boso, N., \& Evans, O. (2018). Drivers of international tourism demand in Africa. Business Economics, 53(1), 25-36. https://doi.org/10.1057/s11369-017-0051-3

Ahmadimanesh, F., Paydar, M.M., \& Asadi-Gangraj, E. (2019). Designing a mathematical model for dental tourism supply chain. Tourism Management, 75, 404-417. https://doi.org/10.1016/j.tourman.2019.06.001

Ajmera, P. (2017). Ranking the strategies for Indian medical tourism sector through the integration of SWOT analysis and TOPSIS method. International Journal of Health Care Quality Assurance, 30(8), 668-679. https://doi.org/10.1108/IJHCQA-05-2016-0073

Al-Talabani, H., Kilic, H., Ozturen, A., \& Qasim, S.O. (2019). Advancing medical tourism in the United Arab Emirates: Toward a sustainable health care system. Sustainability (Switzerland), 11(1). https://doi.org/10.3390/su11010230

Adroit Market Research (2018). https://www.adroitmarketresearch.com/industry-reports/dental-tourism-market

Arulmozhi, S.J., Praveenkumar, K., \& Vinayagamoorthi, G. (2019). Medical tourism in India. International Journal of Recent Technology and Engineering, 8, 695-698. https://doi.org/10.35940/ijrte.B1123.0982S1019

Baltacioglu, T., Ada, E., Kaplan, M.D., \& Yurt, O. (2007). A New Framework for Service Supply Chains. The Service Industries Journal, 27(2), 105-124. https://doi.org/10.1080/02642060601122629

Bolumole, Y.A., Knemeyer, A.M., \& Lambert, D.M. (2003). The customer service management process. The International Journal of Logistics Management, 14(2), 15-31. https://doi.org/10.1108/09574090310806576 
Boyce, C., \& Neale, P. (2006). Conducting in-depth interviews: A guide for designing and conducting in-depth interviews for evaluation input. Pathfinder international tool series: Monitoring and evaluation, 2.

Bryman, A., \& Bell, E. (2011). Business Research Methods. New York: Oxford University Press Inc.

Cengiz, E., Akdu, S., \& Bostan, M.K. (2015). Service recovery strategies in health service. Gümüshane University Electronic Journal of the Institute of Social Science, 12, 87-101.

Chasapopoulos, P., den Butter, F.A.G., \& Mihaylov, E. (2014). Demand for tourism in Greece: a panel data analysis using the gravity model. Int. J. Tourism Policy, 5(3), 173-191. https://doi.org/10.1504/IJTP.2014.063105

Chopra, S., \& Meindl, P. (2004). Supply chain management: Strategy, planning, and operation. Upper Saddle River, N.J: Prentice Hall.

Cho, H.J., \& Lee, T.J. (2019). Stakeholders in the medical trade: The case of South Korea's networks with China and the United States. International Journal of Tourism Research. https://doi.org/10.1002/jtr.2345

Chuang, T.C., Liu, J.S., Lu, L.Y.Y., \& Lee, Y., (2014). The main paths of medical tourism: From transplantation to beautification. Tourism Management, 45, 49-58. https://doi.org/10.1016/j.tourman.2014.03.016

Connell, J. (2006). Medical tourism: Sea, sun, sand and surgery. Tourism Management, 27, 1093-1100. https://doi.org/10.1016/j.tourman.2005.11.005

Croxton, K.L. (2003). The order fulfillment process. The International Journal of Logistics Management, 14(1), 19-32. https://doi.org/10.1108/09574090310806512

Croxton, K.L., García-Dastugue, S.J., Lambert, D.M., Rogers, D.S. (2001). The Supply Chain Management Processes. The International Journal of Logistics Management, 12(2), 13-36. https://doi.org/10.1108/09574090110806271

Croxton, K.L., Lambert, D.M., García-Dastugue, S.J., \& Rogers, D.S. (2002). The demand management process. The International Journal of Logistics Management, 13(2), 51-66. https://doi.org/10.1108/09574090210806423

Dang, H.S., Huang, Y.-F., Wang, C.N., \& Nguyen, T.M.T. (2016). Estimation of the market size of medical tourism industry using grey models-case study in South Korea. Proceedings - International Conference on Computational Intelligence and Applications (46-50). https://doi.org/10.1109/ICCIA.2016.14

Debata, B.R., Patnaik, B., \& Mahapatra, S.S. (2012). An integrated approach for service quality improvement in medical tourism: An Indian perspective. Int. J. Services and Operations Management, 13(1), 119-145. https://doi.org/10.1504/IJSOM.2012.048278

Debata, B.R., Patnaik, B., Mahapatra, S.S., \& Sree, K. (2015). Interrelations of service quality and service loyalty dimensions in medical tourism: A structural equation modeling approach. Benchmarking: An International Journal, 22(1), 18-55. https://doi.org/10.1108/BIJ-04-2013-0036

Denzin, N.K., (1978). The Research Act: A Theoretical Introduction to Sociological Methods, (2nd ed.). New York: McGraw-Hill.

Ellram, L.M., Tate, W.L., \& Billington, C. (2004). Understanding and managing the services supply chain. Journal of Supply Chain Management: A Global Review of Purchasing and Supply, 40(4), 17-32. https://doi.org/10.1111/j.1745493X.2004.tb00176.x

Farmer, C.M., Hosek, S.D., \& Adamson, D.M. (2016). Balancing Demand and Supply for Veterans' Health Care. RAND Health Quarterly, 6(1).

Fernando, Y., \& Lee, H.K. (2015). Dive with the Sharks: A content analysis of the medical tourism supply chain. Current Issues and Emerging Trends in Medical Tourism, 31-43. https://doi.org/10.4018/978-1-4666-8574-1.ch003

Ferrer, M., \& Medhekar, A. (2012). The factors impacting on the management of global medical tourism service supply chain. Journal of GSTF Business Review, 2(2), 206-211. https://doi.org/10.5176/2251-3426_THoR1212

Fitzsimmons, J.A., \& Fitzsimmons, M.J. (2011). Service management: operations, strategy, information technology (7th ed.). 136.

Flick, U. (1992). Triangulation Revisited: Strategy of Validation or Alternative? Journal for the Theory of Social Behaviour, 22, 175-197. https://doi.org/10.1111/j.1468-5914.1992.tb00215.x 
Flick, U. (2004). Triangulation in Qualitative Research. In Flick, U., von Kardorff, E., \& Steinke, I. (Eds.), $A$ Companion to Qualitative Research (178-183). London: Steinke, Sage Publications. https://doi.org/10.1007/978-3-32297512-6

Garrod, B., \& Fyall, A. (2005). Revisiting Delphi: The Delphi technique in tourism research. Tourism research methods: Integrating theory with practice, 85. London, UK: CABI Publishing. https://doi.org/10.1079/9780851999968.0085

Glasner, P. (2009). Cellular division: Social and political complexity in Indian stem cell research. New Genetics and Society, 28(3), 283-296. https://doi.org/10.1080/14636770903151976

Genc, R. (2012). Physical, psychological, and social aspects of QOL medical tourism. Handbook of Tourism and Quality-of-Life Research: Enhancing the Lives of Tourists and Residents of Host Communities, 193-207. https://doi.org/10.1007/978-94-007-2288-0_11

Glinos, I.A., Baeten, R., \& Boffin, N. (2006). Cross-border contracted care in Belgium hospitals. In Rossenmöller M, McKee M, \& Baeten R. (Eds.), Patient mobility in the European Union: Learning from experience. Copenhagen, Denmark: European Observatory on Health Systems and Policies (97-118).

Goldsby, T., \& Garcia-Dastugue, S. (2003). The manufacturing flow management process. The International Journal of Logistics Management, 14(2), 33-52. https:/ / doi.org/10.1108/09574090310806585

Goldstein, S.M., Johnston, R., Duffy, J., \& Raod J. (2002). The service concept: the missing link in service design research? Journal of Operations Management, 20, 121-134. https://doi.org/10.1016/S0272-6963(01)00090-0

Grand View Research (2019). https://www.grandviewresearch.com/press-release/global-medical-tourism-market

Guba, E.G., \& Lincoln, Y. S. (1994). Competing Paradigms in Qualitative Research. In Denzin, N.K., \& Lincoln, Y.S. (Eds). Handbook of Qualitative Research. Thousand Oaks, CA: Sage.

Haksever, C., \& Render, B. (2013). Service Management: An Integrated Approach to Supply Chain Management and Operations. FT Press.

Healthcare Travel Coordination Council. (2012). Assistance companies in medical travel, 6/11/2018. http://www.saturk.gov.tr/images/pdf/tyst/08.pdf

Iranmanesh, M., Moghavvemi, S., Zailani, S., \& Hyun, S.S. (2018). The role of trust and religious commitment in Islamic medical tourism. Asia Pacific Journal of Tourism Research, 23(3), 245-259.

https://doi.org/10.1080/10941665.2017.1421240

Jain, V., \& Ajmera, P. (2018). Modelling the factors affecting Indian medical tourism sector using interpretive structural modeling. Benchmarking: An International Journal, 25(5), 461-1479. https://doi.org/10.1108/BIJ-03-20170045

Johnson, T.J., \& Garman, A.N. (2015). Demand for international medical travel to the USA. Tourism Economics, 21(5), 1061-1077. https://doi.org/10.5367/te.2014.0393

Johnston, R., Clark, G., \& Shulver, M. (2012). Service operations management: Improving service delivery. England: Edinburg Gate.

Karadayi-Usta, S., \& Serdarasan, S. (2019). A collaborative framework for medical tourism service supply chain operations. Global Developments in Healthcare and Medical Tourism, 188-219. https:/ / doi.org/10.4018/978-1-5225-97872.ch011

Kim, M.S. (2017). Integrative modeling of medical tourism industry's competitiveness and a moderating effect of related experience. Information (Japan), 20(5), 3097-3104.

Kuhn, T.S. (1962). The Structure of Scientific Revolutions. Chicago: University of Chicago Press.

Kumar, S., Breuing, R., \& Chahal, R. (2012). Globalization of Health Care Delivery in the United States through Medical Tourism Globalization of Health Care Delivery in the United States through Medical Tourism. Journal of Health Communication, 17(2), 177-198. https://doi.org/10.1080/10810730.2011.585699

Kumar, A., Ozdamar, L., \& Zhang, C.N. (2008). Supply chain redesign in the healthcare industry of Singapore. Supply Chain Management: An International Journal, 13(2), 95-103. https://doi.org/10.1108/13598540810860930 
Kumar, S., \& Blair, J.T. (2013). U.S. healthcare fix: Leveraging the lessons from the food supply chain. Technology and Health Care, 21, 125-141. https://doi.org/10.3233/THC-130715

Kvale, S. (1983). The qualitative research interview: A phenomenological and a hermeneutical mode of understanding. Journal of Phenomenological Psychology, 14, 171-196. https:/ /doi.org/10.1163/156916283X00090

Lambert, D.M., \& Cooper, M.C. (2000). Issues in Supply Chain Management. Industrial Marketing Management, 29(1), 65-83. https://doi.org/10.1016/S0019-8501(99)00113-3

Lambert, D.M. (2009). Customer relationship management as a business process. Journal of Business \& Industrial Marketing, 25(1), 4-17. https://doi.org/10.1108/08858621011009119

Lambert, D.M., \& Schwieterman, M.A. (2012). Supplier relationship management as a macro business process. Supply Chain Management: An International Journal, 17(3), 337-352. https:/ / doi.org/10.1108/13598541211227153

Lambert, D.M., \& Enz, M.G. (2017). Issues in Supply Chain Management: Progress and potential. Industrial Marketing Management, 62, 1-16. https:/ / doi.org/10.1016/j.indmarman.2016.12.002

Lee, H.K., \& Fernando, Y. (2015). The antecedents and outcomes of the medical tourism supply chain. Tourism Management, 46, 148-157. https://doi.org/10.1016/j.tourman.2014.06.014

Legard, R., Keegan, J., \& Ward, K. (2003). In-depth Interviews. In: Richie, J., \& Lewis, J. (Eds.), Qualitative Research Practice (139-168). London: Sage.

Lin, H. (2014). Assessment of the partnership quality between travel agencies and healthcare organizations on the international medical tourism market in Taiwan. Journal of Quality Assurance in Hospitality \& Tourism, 15(4), 356-381. https://doi.org/10.1080/1528008X.2014.921777

Lin, C.T., Lee, I.F., \& Huang, Y.L. (2009). Forecasting Thailand's medical tourism demand and revenue from foreign patients. Journal of Grey System, 21(4), 369-376.

Lincoln, Y.S., \& Guba, E. (1985). Naturalistic Inquiry. Beverly Hills, CA: Sage. https://doi.org/10.1016/01471767(85)90062-8

Loh, C.P.A. (2015). Trends and structural shifts in health tourism: Evidence from seasonal time-series data on health-related travel spending by Canada during 1970-2010. Social Science and Medicine, 132, 173-180. https://doi.org/10.1016/j.socscimed.2015.03.036

Loh, C.P.A., \& Triplett, R.E. (2019). International accreditation, linguistic proximity and trade in medical services. Social Science and Medicine, 238. https://doi.org/10.1016/j.socscimed.2019.112403

Lunt, N. (2015). Networks and supply chains: The nature of medical tourism markets. Handbook on Medical Tourism and Patient Mobility, 184-192. https://doi.org/10.4337/9781783471195.00028

Malairajan, R.A., Ganesh, K., Qureshi, M.N., Anbuudayasankar, S.P., \& Lee, T.-R. (2012). Study of multicommodity network flow problem for the patient distribution system. International Journal of Logistics Systems and Management, 12(1), 70-88. https://doi.org/10.1504/IJLSM.2012.047059

Mason, A.M., \& Spencer, E. (2017). Health communication: insights for quality hospitality bridging healthcare $(\mathrm{H} 2 \mathrm{H})$ delivery in medical tourism. In F.J. DeMicco (Ed.), Medical Tourism and Wellness: Hospitality Bridging Healthcare, 127-145. https://doi.org/10.1201/9781315365671-8

McQuilken, L., Robertson, N., Abbas, G., \& Polonsky, M. (2018). Frontline health professionals' perceptions of their adaptive competences in service recovery. Journal of Strategic Marketing.

https://doi.org/10.1080/0965254X.2018.1511630

Medhekar, A., Wong, H.Y., \& Hall, J. (2014). Medical tourism: A conceptual framework for an innovation in global healthcare provision. Hospitality, Travel, and Tourism: Concepts, Methodologies, Tools, and Applications, 1, $198-221$. https://doi.org/10.4018/978-1-4666-4671-1.ch009

Medhekar, A., \& Haq, F. (2015). Halal branding for medical tourism: Case of Indian hospitals. Emerging Research on Islamic Marketing and Tourism in the Global Economy, 160-189. https://doi.org/10.4018/978-1-4666-6272-8.ch008 
Mohd Isa, S., Lim, G.S.S., \& Chin, P.N. (2019). Patients' intent to revisit with trust as the mediating role: lessons from Penang Malaysia. International Journal of Pharmaceutical and Healthcare Marketing, 13 (2), 140-159. https://doi.org/10.1108/IJPHM-10-2017-0056

Mordor Intelligence Report (2020). Global Medical Tourism Market Report. https://www.mordorintelligence.com/industry-reports/medical-tourism-market

Muljo, H.H., \& Pardamean, B. (2013). Information systems strategic planning for a naval hospital, Lecture Notes in Computer Science, 202-213. https://doi.org/10.1007/978-3-642-36818-9_21

Murray, M., \& Berwick, D.M. (2003). Advanced Access Reducing Waiting and Delays in Primary Care. $J A M A$, 289(8), 1035- 1040. https://doi.org/10.1001/jama.289.8.1035

Nadiri, H., \& Tanova, C. (2016). What factors influence employee service recovery performance and what are the consequences in health care? Quality Management in Health Care, 25(3), 162-175.

https://doi.org/10.1097/QMH.0000000000000104

Nilashi, M., Samad, S., Manaf, A.A., Ahmadi, H., Rashid, T.A., Munshi, A., et al. (2019). Factors influencing medical tourism adoption in Malaysia: A DEMATEL-Fuzzy TOPSIS approach. Computers and Industrial Engineering, 137. https://doi.org/10.1016/j.cie.2019.106005

Perkumiene, D., Vienažindiene, M., \& Švagždiene, B. (2019). Cooperation perspectives in sustainable medical tourism: The case of Lithuania. Sustainability (Switzerland), 11(13). https://doi.org/10.3390/su11133584

Pitt, M., Chotipanich, S., Issarasak, S., Mulholland, K., \& Panupattanapong, P. (2016). An examination of facility management, customer satisfaction and service relationship in the Bangkok healthcare system. Indoor and Built Environment, 25(3), 442-458. https://doi.org/10.1177/1420326X14555420

Rahman M.K., \& Zailani S. (2017). The effectiveness and outcomes of the Muslim-friendly medical tourism supply chain. Journal of Islamic Marketing, 8(4), 732-752. https://doi.org/10.1108/JIMA-11-2015-0082

Rahman, M.K. (2019). Medical tourism: tourists' perceived services and satisfaction lessons from Malaysian hospitals, Tourism Review, 74(3), 739-758. https://doi.org/10.1108/TR-01-2018-0006

Ramos, C.M.Q., \& Rodrigues, P.M.M. (2013) Research note: The importance of online tourism demand. Tourism Economics, 19(6), 1443-1447. https://doi.org/10.5367/te.2013.0253

Rogers, D.S., Lambert, D.M., Croxton, K.L., García-Dastugue, S.J. (2002). The Returns Management Process. The International Journal of Logistics Management, 13(2), 1-18. https://doi.org/10.1108/09574090210806397

Rogers, D.S., Lambert, D.M., Knemeyer, A.M. (2004). The Product Development and Commercialization Process. The International Journal of Logistics Management, 15(1), 43-56. https:/ / doi.org/10.1108/09574090410700220

Sanden, R., Everwijn, H., Rouwette, E., \& Gubbels, J. (2005). Balancing supply and demand for dementia care in the Netherlands. The Town planning review, 1-23.

Sadeh, E., \& Garkaz, M. (2019). Interpretive structural modeling of quality factors in both medical and hospitality services in the medical tourism industry. Journal of Travel and Tourism Marketing, 36(2), 253-267.

https://doi.org/10.1080/10548408.2018.1527273

Sedianingsih, Ratnasari, R.T., Prasetyo, A., \& Hendarjatno (2019). Antecedents of recommendation and repurchase intention on medical tourism. Opcion, 35 (Special Issue 23), 1277-1300.

Shostack, G.L. (1982). How to Design a Service. European Journal of Marketing, 16(1), 49-63. https://doi.org/10.1108/EUM0000000004799

Sterman, J.D., (1982). The Growth of Knowledge: Testing a Theory of Scientific Revolutions with a Formal Model, MIT Sloan School of Management Working paper, 1326-1382.

Tang, C.F., \& Abdullah, A.S.N. (2018). Can inbound medical tourism boost Malaysia's economic growth? Tourism and Hospitality Research, 18(4), 505-513. https://doi.org/10.1177/1467358416682069

Tang, C.F., \& Lau, E. (2017). Modelling the demand for inbound medical tourism: The case of Malaysia. International Journal of Tourism Research, 19(5), 584-593. https://doi.org/10.1002/jtr.2131 
Tenth Development Plan of Turkey (2018). http://www.sbb.gov.tr/wp-content/uploads/2018/11/Onuncu-Kalk $\%$ C4\%B1nma-Plan $\%$ C4\%B1-2014-2018.pdf

Tripathi, V., Elneil, S., \& Romanzi, L. (2018). Demand and capacity to integrate pelvic organ prolapse and genital fistula services in low-resource settings. International Urogynecology Journal, 29, 1509-1515.

https://doi.org/10.1007/s00192-018-3561-2

Um, K.H., \& Kim, S.M. (2018). Application of Fairness Theory to Medical Tourists' Dissatisfaction and Complaint Behaviors: The Moderating Role of Patient Participation in Medical Tourism. Journal of Social Service Research, 1-18. https://doi.org/10.1080/01488376.2018.1436633

Vetitnev, A., Kopyirin, A., \& Kiseleva, A. (2016). System dynamics modelling and forecasting health tourism demand: the case of Russian resorts. Current Issues in Tourism, 19(7), 618-623. https://doi.org/10.1080/13683500.2015.1076382

Wilson, A., Zeithaml, V.A., Bitner, M.J., \& Gremler, D.D. (2016). Services Marketing, Third European Edition, McGraw-Hill Education, 541-542.

Wirtz, J. (2016). Balancing demand and capacity. Winning in Service Markets, 308-343. https://doi.org/10.1142/9781944659066_0009

Wu, W.Y., Qomariyah, A., Sa, N.T.T., \& Liao, Y. (2018). Hospitality Industry: An Application of QFD and ANP. International Journal of Hospitality Management, 75, 48-57. https://doi.org/10.1016/j.ijhm.2018.03.010

Xu, Y., Prats, X., \& Delahaye, D. (2018). Synchronization of Traffic Flow and Sector Opening for Collaborative Demand and Capacity Balancing. IEEE. https://doi.org/10.1109/DASC.2018.8569789

Yang, E.C.L., Khoo-Lattimore, C., \& Arcodia C. (2017). A systematic literature review of risk and gender research in tourism. Tourism Management, 58, 89-100. https://doi.org/10.1016/j.tourman.2016.10.011

Yao, S., Wang, X., Yu, H., \& Guchait, P. (2019). Effectiveness of error management training in the hospitality industry: Impact on perceived fairness and service recovery performance. International Journal of Hospitality Management, 79, 78-88. https://doi.org/10.1016/j.ijhm.2018.12.009

Journal of Industrial Engineering and Management, 2020 (www.jiem.org)

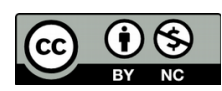

Article's contents are provided on an Attribution-Non Commercial 4.0 Creative commons International License. Readers are allowed to copy, distribute and communicate article's contents, provided the author's and Journal of Industrial Engineering and Management's names are included. It must not be used for commercial purposes. To see the complete license contents, please visit https://creativecommons.org/licenses/by-nc/4.0/. 